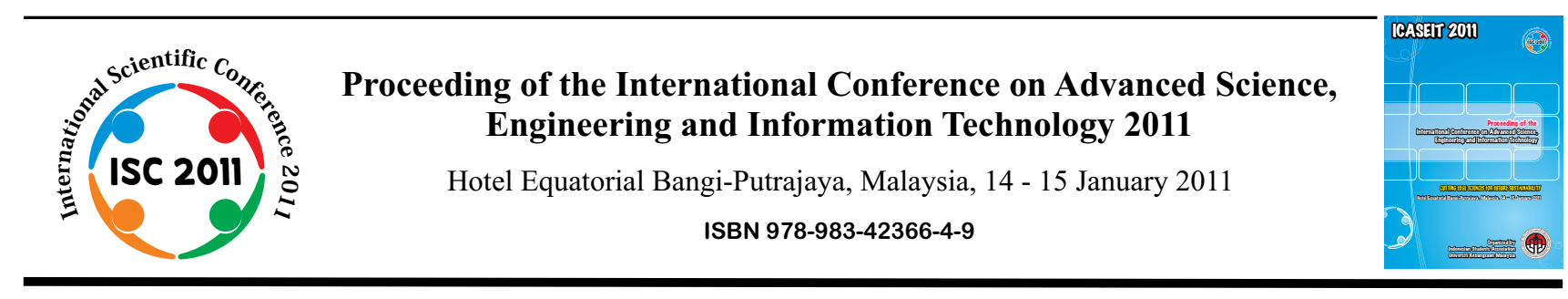

\title{
The Influence of Knowledge Visualization on Externalizing Tacit Knowledge
}

\author{
Khairul Bariah Ahmad ${ }^{1}$, Mazida Ahmad', Mawarny Md Rejab ${ }^{3}$ \\ Information Technology Building, College of Arts and Sciences \\ University Utara Malaysia, 06010 UUM, Sintok Malaysia \\ Tel.:+6049284616,Email: kbariah@uum.edu.my', mazida@uum.edu.my'2,mawarny@uum.edu.my ${ }^{3}$
}

\begin{abstract}
The process of teaching and learning suffers from poor conceptualizations of tacit knowledge to be explicit. This paper interprets and externalizes lecturer tacit knowledge based on knowledge visualization approach. Externalization process is a process of converting tacit knowledge such as ideas and experiences into written form so that it can be transferrred to the students. Thus knowledge visualization is used as an approach to externalize lecturer tacit knowledge through teaching material to be shared among the students. An exploratory research is adapted to discuss the issue of externalization process based on knowledge visualization approach. A conceptual framework is developed which provides an analytical perspective on externalizing tacit knowledge. The results of this study reveal that knowledge visualization is one of the approaches to convert lecturer tacit knowledge to student explicit knowledge in teaching and learning process.
\end{abstract}

Keywords — knowledge externalization, knowledge visualization, knowledge transfer.

\section{INTRODUCTION}

The process of learning in higher education are quite challenging and demanding. Students need to meet a high performance standard of achievement in order to maintain their result. Students' achievements are based on their performance towards assignment, quizzes, test, project and examination. Apparently, at the end of every semester, the students are being evaluated and their grades are given based on their achievement. In order to maintain the grade, they need to have a better understanding on every subject carried throughout the semester. The significant role in transferring the knowledge to the student is the educator or the lecturer. The lecturer acts as an experience person with intelligence that contributes or transfer the knowledge or ideas to the student [1]. Whereas the students or the learners access or transform the knowledge by gaining competence in seeking meaning and understanding [2][3]. Unfortunately, most of the knowledge is in tacit form and difficult to externalized [1]. Which means that with the available support of teaching material being used in the lecture such as lecture notes, slide presentations and explanations from the lecturer seems insufficient to increase students' understanding. The key challenges are: How to measure the percentage of knowledge transfer from the lecture to the student? How to find a way to improve knowledge transfer? How to make learners able to successfully formalize the knowledge from the lecturer?

Most of the human brain's activity deals with processing and analysing visual images [4]. Images are processed first in the brain because it required less energy to be consumed [7]. Furthermore, some experimental results showed that the visual representation produced better result in knowledge acquisition or tasked performance compared to textual view [4]. The use of visual metaphor and abstract images, are effective for transferring knowledge, supporting learning, focus attention and coordinate communication [7][8]. Knowledge visualization actualizes visual representation to transform tacit knowledge to explicit knowledge, promotes learning and annex better understanding towards knowledge [5]. By making the knowledge visible, it can be easily accessible, discussed, valued or generally managed [6]. Thus, this paper describes how knowledge visualization will improve learning and help students to successfully externalize the knowledge. The conceptual framework of knowledge visualization in 
externalization process was proposed based on the previous framework design by [7]. This paper is organized as follows: First section highlights the importance concepts in knowledge management: knowledge type; externalization process; externalization in learning. The second section describes the knowledge visualization: definition; framework. The last part focuses on the conceptual framework of knowledge visualization in externalization process.

\section{KNOWLEDGE MANAGEMENT}

Knowledge management is very important for organizations and enterprises, in which knowledge creation is very important [1]. Thus, knowledge creation is gaining wide acceptance in educational setting to promote discovery of new knowledge. Lecturer transfers ideas and experiences through teaching material to develop student ability in discovering new knowledge.

\section{A. Knowledge Type}

Knowledge is becoming a competitive advantage [1] and importance source in any organization [30]. In general, knowledge includes instincts, ideas, rules, and procedures [40] that guide actions and [14]. Knowledge is divided into two types, tacit and explicit knowledge [8][34]. Tacit knowledge is hard to formalize and difficult to codify. While explicit knowledge can be expressed in words and numbers [32]. [25] described tacit knowledge in online environments as personal, difficult to communicate to others, problematic and contextual. However, in the age of rapid technology expansion, tacit knowledge can be articulated via knowledge visualization technology [1].

\section{B. Externalization Process}

[31] introduced four modes of knowledge creation called SECI model consisting of socialization, externalization, combination and internalization that involved interaction and transaction of tacit knowledge and explicit knowledge. Socialization is the process of transferring experience or tacit knowledge through social interactions such as informal meeting, conversation, and living together. Socialization is a process of sharing experiences and thereby creating tacit knowledge such as shared mental models and technical skills [31]. Externalization means the process of articulating tacit knowledge into written form or explicit knowledge so that it can be shared by others and become the basis of new knowledge. Combination refers to the process of converting explicit knowledge that is inconsistent into a more complex and systematic sets of explicit knowledge. During internalization process, the experiences from previous stages will be converted into valuable knowledge for individual and organization. The spiral indicates the spread of knowledge among individuals or community. The knowledge will be enriching by others and the new knowledge generation will begin dynamically. [40] mentioned, a self-generating loop of knowledge dynamics needs continuous flows of knowledge among the individuals.
Thus, knowledge conversion emphasizes the importance of interaction between tacit and explicit dynamically and consistently. The externalization process mentioned here refers primarily to visualize tacit knowledge into explicit knowledge in teaching and learning environment.

\section{Externalizing in Learning}

Externalization process involves knowledge transformation and knowledge sharing process that are divided into two levels known as transformation process of expert's tacit knowledge to novice explicit knowledge and group explicit knowledge sharing process [25][32]. The processes anticipate organizational learning in individual level, groups and organization. [29] emphasized on the importance of exploring new knowledge and exploiting current knowledge in organizational learning. [37] suggested that organizational learning covers learning from individuals in an organization or employing new individual that possesses the knowledge. According to the views, externalization process is closely related with learning environment covering new knowledge creation process and knowledge sharing process among experts, novices, groups and organization.

In educational field, lecturer's tacit knowledge is transform into students' explicit knowledge in cultivating group learning. Lecturer's tacit knowledge must be complete, broad, details and need to be built from basic knowledge to be understood fairly and becomes students' explicit knowledge, and the knowledge is easy to be transferred to other students. The requirement for the externalization process for the lecturer is substantial because it covers all of the above in ensuring the knowledge being accepted and applied by the student. A number of lecturers from the same field of expertise contribute their expertise in developing teaching materials that are easy to understand and utilize images, symbols and language to be shared in groups that spark students' outcomes. Explicit knowledge is translated into images, symbols and language for better understanding [18]. A clear tacit knowledge is the result from good externalization process that becomes the foundation to a new knowledge [33].

\section{KNOWLEDGE VISUALIZATION}

The process of managing the creation of new knowledge or product innovation involves the visualization of metaphor or ideas into model [31]. Visualization is the ability to build mental pictures or images to draw conclusions, create interpretations and recall details [42] in externalizing tacit knowledge to explicit knowledge [1]. Knowledge visualization lies at the intersection of knowledge management, information visualization, cognitive art, communication sciences and information architecture to improve the transfer, delivery, creation and knowledge understanding between at least two persons or a group of persons [7][1][9]. It thus designates all graphic means that can be used to construct and convey complex insights [3]. The aims of knowledge visualization are to transfer insights, 
experiences, attitudes, values, expectations, perspectives, opinions and predictions [3]. In the next sub-section, the framework of knowledge visualization is discussed further.

\section{A. Knowledge Visualization Framework}

Based on [7], the Knowledge Visualization Framework consists of four main divisions as depicted in Fig.1: A Function Type, Knowledge Type, Recipient Type and Visualization Type.

\begin{tabular}{|c|c|c|c|}
\hline \multirow{2}{*}{$\begin{array}{c}\text { Function } \\
\text { Type }\end{array}$} & & & $\begin{array}{c}\text { Visualization } \\
\text { Type }\end{array}$ \\
\hline & $\begin{array}{c}\text { Knowledge } \\
\text { Type }\end{array}$ & \multirow{2}{*}{$\begin{array}{c}\text { Recipient } \\
\text { Type }\end{array}$} & Sketch \\
\hline Coordination & \multirow{2}{*}{ Know-what } & & Diagram \\
\hline Attention & & Individual & T \\
\hline \multirow{2}{*}{ Recall } & Know-how & \multirow{2}{*}{ Group } & \\
\hline & \multirow{2}{*}{ Know-why } & & Map \\
\hline Motivation & & Organization & Ohis \\
\hline \multirow[b]{2}{*}{ Elaboration } & Know-where & \multirow{2}{*}{ Network } & \\
\hline & \multirow[b]{2}{*}{ Know-who } & & Interactive \\
\hline \multirow[b]{2}{*}{ New Insight } & & & Visualization \\
\hline & & & Story \\
\hline
\end{tabular}

Fig. 1 The Knowledge Visualization Framework

The first division clarifies on behalf of why visualization should be used. A Knowledge Type answers the nature of the content. A Recipient Type stresses on the different backgrounds of the recipient/audience and finally the Visualization Type organizes the main visualization types according to their characteristics. Details of each division will be discussed here.

1) The Function Type: It consists of six different elements of visual representation such as coordination, attention, recall, motivation, elaboration and new insight [7]. The coordination is based on the act of coordinating collaboration. Visual representations help to coordinate students in communication process by utilizing knowledge map, sketches and visual tools. The attention acquires the lecturer to use visual representations in order to get student's attention by addressing emotions, patterns, outliers and trends. While with motivation, the needs of knowledge visualization are crucial. With knowledge visualization, students are eager and willing to do something without being force because they understand and be part of the learning process. Based on [10], there are five elements for successful knowledge transfer: the perceived value of the sender's knowledge, the motivation and willingness of the sender to share the knowledge, the availability and richness of transmission channel, the motivation of the recipient to acquire knowledge from the sender and the absorptive capacity of the recipient. By referring to [10], the motivation element is stresses in both element of the study. The recall and elaboration elements focus on the ability of the student to explain and rebuild their own understanding for certain topics. By using visual representation, student memorability, remembrance, understanding and recall are increase [7]. Finally, for new insight, visual representation supports the creation of new insights by embedding the details in context and illustrates relationships between objects and effects.

2) The Knowledge Type: In order to transfer the knowledge from tacit to explicit knowledge, the type of knowledge need to be identified. Based on [7] there are five types of knowledge being distinguished: Declarative knowledge (refers to the knowledge that answers the question of knowwhat, e.g.: facts), Procedural knowledge (refers to the knowledge that answers the question of know-how, e.g.: processes), Experimental knowledge (refers to the knowledge that answers the question of know-why, e.g.: causes), Orientational knowledge (refers to the knowledge that answers the question of know-where, e.g.: knowledge sources), and Individual knowledge (refers to the knowledge that answers the question of know-who, e.g.: experts or novice).

3) The Recipient Type: The recipient type discusses on the target group which can be an individual, a team, a whole organization or a network of individuals and the context of the recipient in term of cognitive background, experience and previous knowledge. Knowing the target group background is essential for finding the suitable visualization method in transferring knowledge. For instance, the architecture and software engineering students use diagrams to explain concepts, to reduce complexity and amplify cognition [11].

4) The Visualization Type: Visualization types focus on structuring the visualization methods to be used in transferring knowledge. There are seven main method proposed by [7]: Sketches, Diagrams, Images, Maps Objects, Interactive Visualizations and Stories.

Each division have their own characteristics and functions. In order to adapt the framework, all division in the knowledge visualization framework by Burkhard will be used to develop conceptual framework of knowledge visualization in externalization process for education domain.

\section{B. Knowledge Visualization in Externalization Process}

The conceptual framework of knowledge visualization in externalization process is adapted into educational context based on knowledge visualization framework [7]. Lecturer externalized tacit knowledge through teaching material in several visualization approaches. Then student visualized the teaching material as an explicit knowledge to discover new knowledge in enhancing their performance and satisfaction. Elements in conceptual framework are lecturer, teaching material, student and outcome will be discussed separately as depicted in Fig. 2.

1) Lecturer: A lecturer poses as an expert in transferring knowledge [12] [13]. The lecturer is actively involved in social conversion of tacit knowledge with the students regardless of any teaching method. When a lecturer's tacit 
knowledge is externalized into explicit knowledge in the form of teaching material, it is stored in repository as a shared knowledge with the students [36].

2) Teaching Material: Teaching materials can be in the form of syllabus, course notes, books, hyperlinks, quizzes and assignments [19]. A lecturer delivers the material in various formats to be assessable by the students. Visualization is one of the approaches to increase the student's understanding of the material. The course notes can be presented in heuristic sketches, conceptual diagrams, visual metaphor and multimedia representation to stimulate the student's learning process. The students analyse, synthesize and evaluate by reflecting the material [22]. Lecturer's experiences, perceptions and ideas are codified in teaching materials to be distributed among the students.

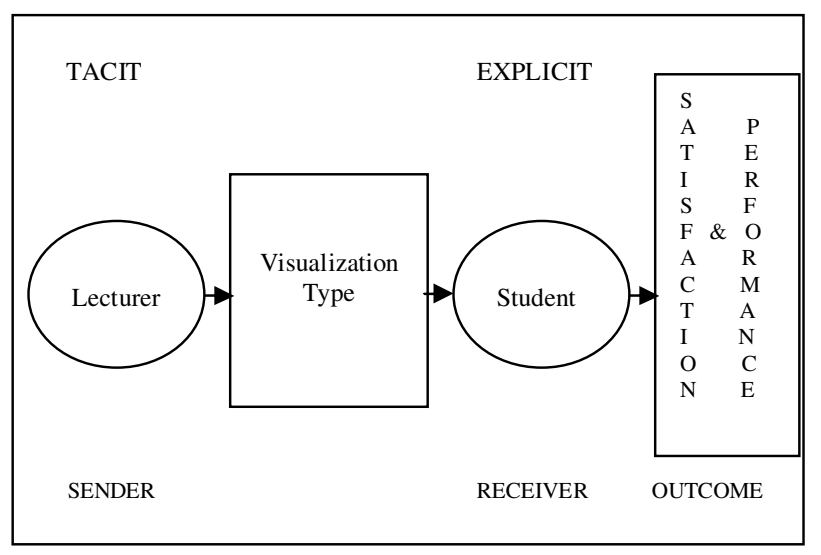

Fig. 2 The Conceptual Framework of Knowledge Visualization in Externalization Process

3) Student: Student is one of the most important variables in learning environment because the learning begins and ends with the student [19]. The students involve in social interaction with their lecturer and colleagues [28] in obtaining tacit and explicit knowledge. During knowledge exploration stage, the students visualize lecturer's tacit knowledge through teaching materials. Their experience and thinking are gathered and revealed among the respective members to form a group of knowledge. Then the knowledge is embodied into an institutional knowledge.

4) Outcome: An effective knowledge transfer from the lecturer to student determines students' performance and satisfaction [15] [16] [27] [35]. The relationship between lecturer, teaching material and student should be well balanced within the learning environment to enhance students' outcomes. The conceptual framework explains a knowledge transformation process involving interaction and transaction between lecturer, teaching material and student in a learning environment. The strength of the connection between the elements becomes the determinant to the outcome of knowledge creation process. [21] explained the two main factors in delivering the knowledge that is velocity, which means the speed of knowledge movement in an organization and viscosity, which is the richness and thickness of the delivered knowledge. The approach of knowledge visualization in learning environment can be explained using [38] theory who stated that students' performance can be uplifted through guidance from a lecturer. The basic idea behind externalization process is the guidance from the expert that can improve students' knowledge to a higher level from the current level through interaction and transaction process opting tacit and explicit knowledge. Knowledge visualization model explains expert's guidance method that exercises [38] theory. The guidance method comes from direct relationship between the lecturer and students through the use of teaching materials in learning environment. The scaffolding introduced by [38] is the process of teaching new knowledge in which students gradually become more responsible in performing their task or applying new knowledge [23].

\section{CONCLUSIONS}

Knowledge visualization is widely being used in externalizing expert's tacit knowledge to novice's explicit knowledge to discover new knowledge. The study will be helpful for the academician to understand the effect of knowledge visualization in externalizing tacit knowledge to explicit knowledge in learning environment. The externalization of tacit knowledge requires lecturer to be aware of various visualization approaches to be taught and that would make critical components of their tacit knowledge explicit.

\section{FUTURE RESEARCH}

A conceptual framework has been proposed based on the literature review that will be tested by gathering data from lecturers and students who use visualization approach in learning environment. The model is tested by using Structural Equation Modeling (SEM) to identify the significant direct relationship effect between the elements in the model. It is a technique to analyze causal relationship among the independent and dependent variables and test fit of a model with the data [24]. SEM is a technique of analysis that includes measurement error to comprehend other influencing indicator [20][26]. Any finding based on the test will be used to revise the conceptual model.

\section{REFERENCES}

[1] Y. Zhang, X. He, J. Xie \& Z. Wang (2008). Study on the Knowledge Visualization and Creation Supported Kmap Platform. IEEE Xplore. Downloaded on August 05, 2010.

[2] G. Qianyi, S. Tamara \& A. Faisal (2010). Improving Conceptual Learning through Customized Knowledge Visualization. IEEE Xplore Downloaded on July 27, 2010.

[3] C.C. Kuhlthau. Seeking Meaning: A Process Approach to Library and information Services. Libraries Unlimited, 2004.

[4] Z. Yuan \& S. Xin (2008). The Research on Ontology-based Knowledge Visualization in E-Learning Resources Management. IEEE XPlore. Downloaded on July 27, 2010.

[5] J. Zhang, D. Zhong \& J. Zhang (2010). Knowledge Visualization: An Effective Way of Improving Learning. IEEE Xplore. Downloaded on July 27, 2010. 
[6] X. Y. Wang \& Y. Mu (2009). Visualization based on Concept Maps: an Efficient Way to Knowledge Sharing and Knowledge Discovery in E-Science Environment. IEEE Xplore. Downloaded on July 27, 2010 .

[7] R. A. Burkhard (2004). Learning from architects: The difference between knowledge visualization and Information visualization. IEEE Xplore. Downloaded on July 27, 2010.

[8] I. Nonaka (1991). The knowledge-creating company. Harvard Business Review, 69, 96-104. Retrieved August 22, 2008.

[9] Y. Y. Chen \& H. S. Xia (2009). Knowledge Construction Based on Visualization E-learning in Digital Library.

[10] V. Gupta \& V. Govindarajan. "Knowledge Flows within Multinational Cooperation", Strategic Management Journal, 2000, 21(4), pp.473-496.

[11] R. A. Burkhard \& M. Meier. "Tube Map Visualization: Evaluation of a novel Knowledge Visualization Application for the Transfer of Knowledge in Long-Term Projects", Journal of Universal Computer Science, Vol. 11, no. 4 (2005), 473-494

[12] M. Ally (2004). Foundations of educational theory for online learning. In Anderson, T., \& Elloumi, F. (Eds.), Theory and Practice of Online Learning (pp. 3-31) Canada: Athabasca University. Retrieved August 22, 2008.

[13] T. Anderson (2004). Toward a theory of online learning. In T Anderson \& F. Elloumi (Eds.), Theory and practice of online learning (pp. 33-60). Canada: Athabasca University. Retrieved August 4, 2008.

[14] C. Barreto \& M. D. Eredita (2004). Unraveling expertise and knowledge creation: towards an instance-based model of knowledge (IMoK). Proceedings of the 37th Hawaii International Conference on System Sciences, pp.1-11.

[15] S. Carliner (2004). An overview of online learning. MA: HRD Press, Inc.

[16] N. S. Chen, C. W. Wei, Kinshuk, Y. R. Chen, \& Y.C. Wang (2008) Bridging the gap between face-to-face and cyber interaction in holistic blended learning environments. In Adelsberger, $\mathrm{H} . \mathrm{H}$, Kinshuk, Pawlowski, J. M., \& Sampson, D. (Eds.), Handbook on information technologies for education and training (pp. 239-259). Heidelberg: Springer.

[17] N. S. Chen, C. W. Wei, Kinshuk, Y. R. Chen \& Y.C. Wang (2008) Bridging the gap between face-to-face and cyber interaction in holistic blended learning environments. In H. H. Adelsberger, Kinshuk, J. M. Pawlowski, \& D. Sampson (Eds.), Handbook on information technologies for education and training (pp. 239-259). Heidelberg: Springer.

[18] S. W. Chou, \& M. Y. He (2004) Facilitating knowledge creation by knowledge assets. Proceedings of the 37th Hawaii International Conference on System Sciences - 2004, pp.1-10.

[19] J.G.S. Clawson (2006). Fundamental elements in teaching. In J. G. S Clawson, \& M. E. Haskins (Eds.), Teaching management (pp.12-25). Cambridge: Cambridge University Press.

[20] S. Conley, D. E. Muncey, \& S. You (2005). Standards-based evaluation and teacher career satisfaction: a structural equation modeling analysis. J Pers Eval Educ, 18, 39-65.

[21] T. H. Davenport \& L. Prusak (1998). Working knowledge: How organizations manage what they know. Massachusetts: Harvard Business School Press.

[22] M. Driscoll \& S. Carliner (2005). Advanced web-based training strategies. CA: John Wiley and Sons, Inc.

[23] T. L. Good, C. R. H. Wiley, \& I. R. Florez (2009). Effective teaching: An emerging synthesis. In Saha, L. J. \& Dworkin, A. G. (Eds.), International handboos of research on teachers and teaching. (pp. 803-816). NY: Springer.

[24] R. Ho (2006). Handbook of univariate and multivariate data analysis and interpretation with SPSS. Boca Raton: Chapman and Hall/CRC.

[25] Y. Jialin (2006). Externalization of tacit knowledge in online environments. International Journal on E-Learning, 5(4), 663-674.

[26] R. B. Kline (2005). Principles and practice of structural equation modeling. NY: THE GUILFORD PRESS.

[27] M. Lucy \& P. J. Guglielmino (2004). Becoming a more self-directed learner. In G.M. Piskurich (Eds.), Getting the most from online learning (pp. 25-38). CA: John Wiley and Sons, Inc.

[28] N. A. Maleh, C.S. Lee, C. K. Ho, \& H. R. Chong (2004). A conceptual framework for enhancing the instructional design process. Malaysian Online Journal of Instructional Technology, 1(2).

[29] D. Liberati (2004). Building successful online relationship. In G.M. Piskurich (Ed.), Getting the most from online learning (pp. 131-144). CA: John Wiley and Sons, Inc.
[30] J. G. March (1991). Exploration and exploitation in organizational learning. Organization Science, 2(1), 71-87.

[31] M. Mokhtar, M. K. Ibrahim, \& N. Nordin (2002). The academic performance of electronic distance learners: an empirical evidence from malaysia. Malaysian Journal of Distance Education, 2(2), 71-89

[32] G. D. Bhatt (2000). Information dynamics, learning and knowledge creation in organizations. The Learning Organization, 7(2), 89-98.

[33] I. Nonaka \& H. Takeuchi (1995). The knowledge creating company: How Japanese companies create the dynamics of innovation. Oxford Oxford University Press. 162

[34] I. Nonaka \& N. Konno (1998). The concept of ba: Building a foundation of knowledge creation. California Management Review, $40(3), 40-55$

[35] I. Nonaka, N. Konno, \& R. Toyama (2001) Emergence of ba : A conceptual framework for the continous and self-transcending process of knowledge creation. In Nonaka, I., \& Nishiguchi, T. (Eds.), Knowledge emergence: social, technical and evolutionary dimensions of knowledge creation (pp. 13-29). Oxford: Oxford University Press.

[36] M. Polanyi (1966). The tacit dimension.NY: Anchor Day Books.

[37] M. J. Rosenberg (2001). E-learning, strategies for delivering knowledge in the digital age. NY: McGraw-Hill.

[38] I. Shehabat, S. A. Mahdi, \& K. Khouadi (2008). E-learning as knowledge management approach for intellectual capital utilization. Turkish Online Journal of Distance Education-TOJDE, 9(1), 205-216.

[39] H. A. Simon (1991). Bounded rationality and organizational learning. Organization Science, 2(1), 125-134.

[40] L. S. Vygotsky (1978). Mind in society. MA: Harvard University Press.

[41] G. D. Bhatt (2000). Information dynamics, learning and knowledge creation in organizations. The Learning Organization, 7(2), 89-98.

[42] E. O. Keene \& S. Zimmerman (1997), Mosaic of Thought, Teaching Comprehension in a Reader's Workshop. NH: Heinemann. 